Rev. Elev. Méd. vét. Pays trop., 1975, 28 (2) : 103-104

\title{
Note sur la rhinotrachéite infectieuse des bovins en Éthiopie: Enquête sérologique préliminaire
}

\author{
par P. C. LEFEVRE (*)
}

\begin{abstract}
RESUME
Au cours d'une enquête sérologique, 387 sérums de bovins ont été testés vis-à-vis du virus de la rhinotrachéite infectieuse pour y rechercher la présence d'anticorps neutralisants. 41,8 p. 100 des sérums ont été trouvés positifs, ce qui traduit une atteinte enzootique du cheptel bovin éthiopien.
\end{abstract}

\section{INTRODUCTION}

Comparée aux fléaux de l'élevage bovin qui sévissent à l'heure actuelle en Ethiopie, la rhinotrachéite infectieuse ne présente pas un intérêt immédiat. En effet, sans tenir compte de la peste bovine et de la péripneumonie en voie d'éradication grâce à la Campagne Conjointe Interafricaine $(1,6)$, d'autres maladies infectieuses comme la fièvre aphteuse (7) ou parasitaires (4) ainsi que les conditions d'élevage doivent avant tout retenir l'attention.

Toutefois, au vu des résultats obtenus dans d'autres pays d'Afrique $(3,9,11)$ et notamment en Tanzanie (10), il a semblé intéressant de réaliser une enquête sur des sérums prélevés aux fins de contrôle de l'immunité anti-bovipestique.

\section{MATERIEL ET TECHNIQUES}

Les sangs ont été prélevés dans deux provinces d'Ethiopie en mars-avril 1974 :

- Province du Sidamo dans le sud (région d'Agare Salam),

- Province du Harrar à l'est (région de Diidjiga).

(*) Mission Vétérinaire Française en Ethiopie (I.E.M.V.T.), Imperial Veterinary Institute, B.P. 19, Debré-Zeit.
Les sérums ont été analysés par séro-neutralisation sur cellules de première explantation de rein de foetus de bovin $(2,5,8)$. La souche de virus utilisée est la souche IBR-LAE à son $5^{\text {t }}$ passage sur cellules de rein de veau, diluée afin d'obtenir de 500 à 1000 DICT $_{50}$ par ml.

La lecture est faite au bout de 48 heures.

\section{RESULTATS}

\begin{tabular}{|c|c|c|c|}
\hline & $\begin{array}{c}\text { Nombre } \\
\text { de sérums }\end{array}$ & Positifs & $\begin{array}{c}\text { Pourcentage } \\
\text { de positifs }\end{array}$ \\
\hline SIDAMO & 146 & 62 & 42,4 \\
HARRAR & 241 & 100 & 41,5 \\
\hline & 387 & 162 & 41,8 \\
\hline
\end{tabular}

(Ethiopie, avril 1974.)

Dans le Harrar, sur 241 sérums, 176 proviennent de femelles dont 79 sont positifs, soit 44 p. 100 , et 65 proviennent de mâles dont 21 sont positifs, soit 32 p. 100 .

Il n'existe donc pas de différences significatives entre les sexes. 
En outre, 114 animaux ont plus de 5 ans et, parmi eux, 79 présentent des anticorps, soit 69 p. 100.

Or il a été démontré récemment (11) que les animaux infectés pouvaient éliminer du virus IBR pendant des années, tout en étant porteurs d'anticorps : il en résulte que le cheptel bovin éthiopien est réinfecté de façon chronique et que la rhinotrachéite évolue sur le mode enzootique.

\section{CONCLUSIONS}

Il apparait donc que la rhinotrachéite infectieuse des bovins est fortement implantée en Ethiopie comme dans le reste de l'Afrique $(3,9,10,11)$ et qu'elle doit, par conséquent, faire l'objet d'une étude approfondie, à savoir : isolement du virus et enquête épizootiologique pour savoir si les deux formes principales (génitale et respiratoire) coexistent ou si l'une des deux prédomine.

Une maladie même secondaire au plan économique ne peut être ignorée surtout quand elle se traduit par un taux d'infection aussi élevé.

\section{Remerciements}

Nos plus vifs remerciements vont au Docteur PERREAU qui a eu l'obligeance de nous envoyer la souche de virus de la rhinotrachéite infectieuse ainsi qu'aux Docteurs DREYFUSS, FEVRIER et GUIDOT qui ont récolté les sérums.

\title{
SUMMARY
}

\section{Report on infectious bovine rhinotracheitis in Ethiopia. Preliminary serological survey}

\begin{abstract}
During a serological survey, 387 bovine sera were tested against infectious rhinotracheitis virus in order to detect neutralizing antibodies. 41,8 p. 100 of the sera were found positive; this percentage meaning an enzootic
\end{abstract}

infection of the ethiopian cattle.

\section{RESUMEN}

Nota sobre la rinotraqueitis infecciosa de Ios bovinos en Etiopia: estudio serologico prelimmario

Durante una encuesta serologica, 387 sueros de bovinos fueron examinados contra el virus de la rinotraqueitis infecciosa. 41,8 por 100 de los sueros se encontraron positivos. Este porcentaje traduce una infeccion de tipo enzootico del ganado etiopiano.

\section{BIBLIOGRAPHE}

1. DOMENECH (J.), LEFEVRE (P.C.). Enquête sur la péripneumonie et la brucellose bovines en Ethiopie. Rev. Elev. Méd. vét. Pays trop., 1975, à paraître.

2. GILBERT (Y), SAURAT (P.), Le complexe de Ia rhinotrachéite infectieuse des bovins. Paris, L'expansion, 1970. (Coll. "Les maladies à virus ").

3. GOSSLER (R.), LEY (W.), HUNERMUND (G.) Serological studies in cattle in the Kabete area of Kenya: 1) Occurence of antibodies against para influenza 3, IBR and BVD viruses, Chlamydia and Coxiella burneti. Berl. Minch. Tierärztl. Wschr., 1973, 86 (9) : 164-166.

4. GRABER (M.). Helminthes et helminthiases des animaux domestiques et sauvages d'Ethiopie. Maisons-Alfort, I.E.M.V.T., 1973.

5. GREIG (A.S) A serum neutralization test for IBR based on colour reaction and cytopathic effect in cell culture Can. J. comp. Med., 1969, 33 : $85-88$.

6. LEFEVRE (P. C.), DOMENECH (J.). Contrôle sérologique de l'immunité conférée par la vac- cination anti-bovipestique en Ethiopie. Rev. Elev. Méd. vét. Pays trop., 1974, 28 (2) : 177-181.

7. MARTEL (J.-L.). La fièvre aphteuse en Ethiopie. Distribution des sérotypes du virus aphteux. Rev. Elev. Méd. vét. Pays trop., 1974, 28 (2) : 169-175.

8. MOHANTY (S. D.), LILLIE (M. C.). A quantitative study of the IBR neutralization test. $A m$. J. vet. Res., 1965, 26 (113) : 892-896.

9. PROVOST (A.), BORREDON (C.), FEREOL (C.). Note sur la rhinotrachéite infectieuse bovine en Afrique Centrale. Rev. Elev. Méd. vét. Pays trop., 1964,17 (2) : 187-196.

10. RWEYEMANU (M.M.). Probable occurence of infectious rhinotracheitis, virus in Tanzania wildlife and cattle. Nature, Lond., 1970, 225 (5234): 738-739.

11. WELLEMANS (G.). Les réactions immunitaires au virus IBR chez les bovins. (à paraître.)

12. ZWART (D.). The virus of infectious bovine rhinotracheite in Northern Nigeria. Bull. epiz. Dis. Afr., 1966, 14 (4): 405-408. 